\title{
Bridging the Motives and Attractor States: How These Dynamics Go While Choosing the Elective English Course?
}

\author{
Angel Hsieh \\ National Changhua University of Education, Changhua, Taiwan
}

\begin{abstract}
This study aimed at investigating and implementing the main triggers for enhancing the motivations of taking an elective English course within the sport college students. The researcher explored and analyzed these triggers as the motivational components under the attractor states. In order to observe the dynamics of these college students who have been regarded as unmotivated with the English courses, the researcher designed a semi-structure interview questions related to the motivational components and observed the process of students' implementation, modification, and the relation with attractor states. This study covered Phase 1 for a think aloud question at the beginning of the semester which conducted to 65 sophomores (35 for PE students and 30 for Dance students). Phase 2 designed as three semi-structured interview questions for $10 \mathrm{PE}$ sophomores and 10 dance sophomores. This interview conducted followed by the midterm presentation. Data analysis is under the discussion of attractor states (Waninge, 2015). This study demonstrates qualitative method to collect data. The qualitative data were collected through several techniques such as observations, reflections, and student interviews. From the findings, these teacher-specific motives trigger these students' intention to make the decision. These students performed better motivation during the learning path till the midterm presentation. Both their English performance and learning motivation were significantly enhanced. Moreover, they had positive attitude toward learning English and they apparently recognized the value of the presentation. The results were shown in positive improvement in the motives with application of attractor states. Furthermore, a teacher-student relationship was built as one of the most precious fruits of the processes.
\end{abstract}

Keywords: L2 motivation, motivational components, attractor states

\section{Introduction}

This chapter includes four sections. First, it introduces the background of the study. That is a brief introduction of motivational components. Second, it indicates the purpose of the study, which presents the discussion of the effect of attractor states. Third, we discuss the research questions in this study, which is the idea of the case study.

\section{Background of the Study}

After observing English learning in Sport Colleges for so many years, many students consider that English skills in the college have been an unnecessary training even the teachers do a huge effort. Even though students are asked to write some English essays from a young age or speak some short dialogue in class, officially in

Angel Hsieh, Ph.D. student, Department of English, National Changhua University of Education, Changhua, Taiwan. 
high schools or privately in cram schools, some students view English as difficult work. In most teaching contexts, the importance of sentence sequencing and grammar correctness are not presented with respect to the pragmatic use as in actual contexts. Rather, it is presented as a means to meet requirements that are considered major motivational forces for students' English skills in further studies. Among the main troubles students are facing, most students cannot acquire the writing skills for the lack of the close connection with teachers' correctness. Or these students lack the confidence to stand in front of other classmates and do some short presentations. Therefore, if students can acquire the benefits from teacher's encouragement, such as teacher-specific motives, they certainly can require the feedback more efficiently.

\section{Purpose of the Study}

The main purpose of the present study aimed at investigating and implementing the main triggers for enhancing the motivations of taking an elective English course within the Sport College students. It was meant to explore the effect of the motivational components on the students' first thought of choosing the elective English course. One objective of the study was to observe how the motivational components work out among these students choosing process. Then, record the reflections step by step to check if these motivational components really did work on the later learning performances for the college students in their midterm presentation. In addition, this study also investigated how the students had changed in terms of their attractor states toward their English performances, and perceived achievements. The last objective was to examine what reflections the teacher as the researcher made on the teaching and on the implementation of the dynamics of motivation field.

\section{Research Questions}

The research questions for this case study were as follows:

1. What are the motivational components for these college students while choosing the elective English course?

2. How do these motives roles show in the process of these students' attractor states?

\section{Literature Review}

\section{L2 Motivation}

L2 motivation refers to students' motivation for learning a second/foreign language. The present study investigated the changes in the students' motivation for English learning. From the early 1990s, there are many researchers exploring the social psychological construct of L2 motivation. Although Gardner (1985) and his associates stated most discussions about L2 motivation in this field, Oxford and Shearin (1994) also mentioned the source of motivation is very important to teachers who want to stimulate students' motivation. The explicit concern of the educational implications has brought a major trend in psychological and educational psychological theories of motivation, which might reflect in L2 motivation theories. Dörnyei (1994; 1998; 2003) discussed a clear framework of three aspects of the motivational construct, which are related to the L2 motivation structures. Among these discussions, Dörnyei mentioned the actual L2 motivation construct is closely associated with the motivation test battery, which is discussed by Gardner and MacIntyre (1993). This conceptualization of measurements in L2 motivation discussion reflects the self-report behavior measures which correlate with motivated behavior. 
From the explicit elaboration of discussions from L2 motivation theories, there are some interesting factors influencing the application of L2 motivation. If these L2 motivation constituents really work on the learning path, there might be a main factor which stands for the basic and necessary component within the L2 motivation research. Gardner and Lambert's (1972) explored the main factor for the success in L2 learning. That is a function of the learner's attitudes towards the linguistic-cultural community of the target language. Thus, the findings of this study added a social dimension to the study of motivation in learning a L2. That inspired the main discussion in the later motivational components which related to the L2 learning.

\section{Motivational Components}

As to the implications of discussion for applying motivation, some studies have extended the previous construct by mixing new components. For instance, there is the interface with intrinsic and extrinsic motivation by Brown (1994) as well as the attribution of motivational theories by Dörnyei (1990) and Skehan (1989). There are also some intrinsic interpretations of various motives related to learning situation-specific variables, such as classroom events and tasks, classroom climate and group cohesion, course content and teaching materials, teacher feedback, and grades and rewards (Dörnyei, 1994; Crookes \& Schmidt, 1991). In order to recognize the variables and processes involved at the learning situations level of L2 motivation, Dörnyei (1994) indicated three sets of motivational components: (1) course-specific motives, which relate to the syllabus, the teaching materials, the teaching method, and the learning tasks; (2) teacher-specific motives, which relate to the teacher's personality, teaching style, feedback, and relationship with students; (3) group-specific motives, which relate to the dynamics of the learning group.

Course-specific motivational components. Based on Keller's motivational system, which is particularly comprehensive and relevant to classroom learning, Crookes and Schmidt (1991) postulate four major motivational factors to describe L2 classroom motivation: interest, relevance, expectancy, and satisfaction. This framework appears to be particularly useful in describing course specific motives. And it also related to one of the later factor influencing learners' attractor states. The first category, interest, concerns with intrinsic motivation and is mainly triggered by the individual's inherent curiosity and desire to know more about learners' environment. That is, learners feel that the instruction is connected to important personal needs, values, or goals. At a broad level, this component coincides with instrumentality. At the level of the learning situation, it refers to that the classroom instruction and course content are seen to be conducive to achieving the goal. That means, to mastering the L2 Expectancy refers to the perceived likelihood of success and is related to the learner's self-confidence and self-efficacy at a general level. If the learners are at the level of the learning situation, it concerns perceived task difficulty, the amount of effort required, the amount of available assistance and guidance, the teacher's presentation of the task, and familiarity with the task type. Other aspect is that satisfaction concerns the outcome of an activity, referring to the combination of extrinsic rewards such as praise or good marks and to intrinsic rewards such as enjoyment and pride. Attainable proximal sub-goals are related primarily to this component (Dörnyei, 1994).

Teacher-specific motivational components. The most important teacher-related motive has been identified in educational psychology as affiliative drive. That is, students need to do well in school in order to please the teacher, or other superordinate figures like parents whom they like and appreciate. Although this desire for teacher approval is an extrinsic motive, it is often a trigger for intrinsic interest. Good teachers always can make their students become devoted to their subject. A second teacher-related motivational component is 
the teacher's authority type. That is, teachers need to be autonomy supporting or controlling. They have to share responsibility with students, offer students' options and choices, encourage them to set priorities, and involve them in the decision making enhance student self-determination and intrinsic motivation. A third motivational aspect of the teacher is the role in direct and systematic socialization of student motivation. That is, teachers can actively develop and stimulate learners' motivation. There are three main aspects for the socialization process: (1) Modelling: Teachers, in their position as group leaders, embody the "group conscience" and, as a consequence, student attitudes and orientations toward learning will be modeled after their teachers, both in terms of effort expenditure and orientations of interest in the subject. (2) Task presentation: Efficient teachers draw students' attention to the purpose of the activity they are going to do, its potential interest and practical value, and even the strategies that may be useful in achieving the task; hence raising students' interest and metacognitive awareness. (3) Feedback: This process carries a clear message about the teacher's priorities and is presented in the students' motivation. Two types of feedback are shown: informational feedback, the more dominant one, which comments on competence; as well as the controlling feedback, which judges performance against external standards. For instance, praise-a type of informational feedback should attribute success to effort and ability, implying that similar successes can be expected in the future. However, praise should avoid the inclusion of controlling feedback, like the comparison of the students' success to the successes or failures of others. Ames (1992) points out that social comparison, which is considered very detrimental to intrinsic motivation, is often imposed in a variety of ways in the classroom, including announcement of grades, which is sometimes only the highest and lowest, displays of selected papers and achievements, and ability grouping.

Group-specific motives. As to this specific domain of L2 motivation, four aspects of group-specific motives are: (1) goal-orientedness, (2) norm and reward system, (3) group cohesion, and (4) classroom goal structures (Dörnyei, 1994). With respect to the goal of a group of students, having fun is rather than to learn. Goal-orientedness refers to the extent to which the group is adjusted to pursuing its goal of L2 learning. Norm and reward system is the most salient classroom factor that affects learners' motivation. That means extrinsic regulations should be internalized as much as possible to trigger intrinsic motivation (Dörnyei, 1994). The group norms and rewards are standards that the majority of group members totally agree to and these become part of the group's value system. Hence, once a norm has been internalized and becomes a self-evident precondition for the group to act, the group is willing to deal with the derivations by putting pressure on members who violate the norm. The possible group behaviors might happen: to show active support to teachers' efforts to observe the norms, to indirectly express disagreement with and dislike for some members, and openly to criticize them and put them in the stance of social quarantine.

As to the findings of Clément, Dörnyei, and Noels (1994), they confirmed the group cohesion is an important motivational component in a L2 learning context. Due to the fact in a cohesive group, members are willing to achieve the group success and the group's goal-oriented norms indeed trigger a strong effect over the individual. With view to the discussion of classroom goal structures, it can be competitive, cooperative, or individualistic. The cooperative goal structure is the most powerful factor while promoting intrinsic motivation. It also can reach less anxiety, greater task involvement, and a more positive emotional tone. If the cooperative goals work, it triggers the positive attitudes towards the subject area, as well as a cohesive relationship with classmates and with the teachers (McGroarty, 2001). As to the core of this study, researcher wants to explore 
the possible relation within motives and attractor states, especially in the dynamics of motivation process. The explicit discussion of attractor states and motives will be illustrated later.

\section{Attractor States}

With view to a dynamic perspective on motivation and the concept of conglomerates, L2 learning experiences as representing affective to cognitive motivational conglomerates on a relatively short-term timescale in the overall context of a classroom. These dynamic states are central to understanding a learner's overall motivational profile. From so many previous discussions of researches, a context as complex as a classroom setting could produce an endless variety of possible states for learners to experience. Nevertheless, the self-organization process within dynamic systems helps to offer order and consistency. It shows that there are a number of states occurring more frequently than others in educational contexts. The best way to understand the nature of the learning experience is to identify these recurring attractor states towards which the system tends to operate. The precious literature reviews proposed a set of possible states, four of which will be examined in this study.

First state which can be described is engagement. Often recognized as being a subset of Csikszentmihalyi's (1990) concept of flow, engagement means that the student is immersed in and focused on the task (Mercedes \& Rodrigo, 2011). Whereas there is certainly an overlap between engagement and flow (D’Mello \& Graesser, 2012), they combine the two into one classroom-state, using the term "engagement/flow". It is important to note that one can be engaged without experiencing flow proper; that is, when it is accompanied by anxiousness while avoiding a negative outcome like failing an exam or getting a poor score. Yet, the learner experiences flow which contains the culmination of concentration, interest, and enjoyment. There is an added layer of experience; that is, a loss of self-consciousness and distortion of time (Shernoff, Csikszentmihalyi, Schneider, \& Shernoff, 2003). Another related attractor state is interest. Interest is often viewed as motivational variable in the educational context (Ainley, 2007; Hidi, Renninger, \& Krapp, 2004). It also investigates in Gardner's (1985) Attitude/Motivation Test Battery in the form of "interest in foreign languages”. As to Ainley (2007), it is a key component of engagement in academic tasks. Although it is sometimes labeled as an emotion (Silvia, 2005) and is even placed as the first place among these emotions together with fear, disgust, enjoyment, and sadness (Izard, 2011), the exact definition is still open for investigation. However, rather than classifying interest as either an affective, motivational, or cognitive state, there has been a tendency to describe the phenomenon as a conglomerate of affective, cognitive, and motivational processes (Ainley, 2007; Dörnyei, 2009). In fact, this approach has a long history as over a century ago Dewey also Motivation, Emotion and Cognition described "interested" as a complex affective-cognitive structure (Dewey, 1913).

Later theories depict interest as a motivational variable that combines affective and cognitive functioning (Hidi et al., 2004), and similarly, Ainley suggests that interest is a combined effect of cognition, emotion, and motivation: The general point is that there are functional combinations of affective and cognitive processes, which persist across time as organized processing structures (Ainley, 2007).

A third state can be called anxiety, one of the traditional individual difference variables in applied linguistics. That is, as Dörnyei (2009) calls it, “a curious variable”. First, anxiety has been examined both as a stable personality trait and as a transient state (Dewaele, Petrides, \& Furnham, 2008). Second, whereas it has been related negatively to language learning and language processing (MacIntyre \& Gardner, 1994), if the level 
of arousal is not too high for the individual student, it can also increase effort and can thus have a positive effect on learning outcomes (MacIntyre, 2002). As to the discussion of interest, anxiety seems to have affective, motivational, and cognitive components: It is related to one of the basic emotions, like fear, in Izard (2011). It presents in theories of motivation and self-confidence (Gardner, 2004), as well as cognitive appraisals (Pekrun, Goetz, Titz, \& Perry, 2002) and worry by Dörnyei (2005). A fourth state is boredom. Since it is familiar to both teachers and students, boredom has received less research attention than the states mentioned above. Most recent research into boredom has been done by Pekrun and colleagues (Pekrun et al., 2002; Pekrun, Goetz, Daniels, Stupnisky, \& Perry, 2010), who proposed boredom as one of the "achievement emotions”. These researchers summarize boredom as a state composed of unpleasant feelings, a lack of cognitive stimulation and low physiological arousal, a sense of time passing slower than usual and a tendency to disengage from the activity. That is, it combined affective, cognitive, and motivational characteristics into one state. Some studies indicate that boredom is the most enduring of any states in a classroom environment, whereas engagement, confusion, and frustration seem to be relatively shorter lived (D’Mello \& Graesser, 2012; Mercedes \& Rodrigo, 2011). Boredom was originally thought to be caused by a lack of challenge. When ability is high and demands are low, boredom is elicited. Whereas the research suggests that students are overwhelmed with information and feel unable to solve the task presented, or cannot follow the on-going discussion, they are also likely to be bored or to zone out (Lee Do \& Schallert, 2004; Pekrun et al., 2010).

\section{Relation Between Motives and Attractor States}

That is uncommon to see the discussion of the relation between motivational components and attractor states in current English classes, especially in the elective courses in Sport Colleges. That is because the English skills are the most difficult program in Sport Colleges' curriculum. These sport majors learners cannot achieve their learning efficacy with certain specific performance in motives. This study assumes there might be some possible connection between motivational components and attractor states. Another possible factor to show the influence of motivational components is the idea of self-efficacy. As to the limitation of the methodology of this study, there cannot prove the influence on self-efficacy by qualitative study. Besides, if learners' receive a strong sense of self-efficacy, it can enhance their achievement behavior by helping them to approach threatening situations with confidence. That is an apparent result from the inference of the rationale of this study. Although the self-efficacy perceptions are not easy to measure in the teacher's reflection journal, it still can show some insights related to the cognitive aspects in the self-efficacy fields. Self-efficacy beliefs are related to actual competence and abilities indirectly while they are making the product of a complex process of self-persuasion based on cognitive processing of diverse sources. In the present study, self-efficacy refers to the students' perception about their confidence in their ability to perform in the midterm presentation on stage. The strength of perceived self-efficacy was measured qualitatively. As to the qualitative data, it was collected from the teacher's observations, and the students' interviews.

\section{Method}

\section{Rationale for the Choice of Research}

This study provides the educational action research as the rationale of research method. Action research allows making modifications in progress and the same process may be run repeatedly until a better solution is found. The teachers can see the main learning problem through students' interviews and teachers' observation 
in the real action research. In view of the flexibility and the recursion of action research, the nature of action research fits into the design of the study. According to Kemmis and McTaggart (1988), the complementary and dynamic process of action research goes through four steps, that is, planning, action, observation, and reflection. The fundamental steps of action research are in accordance with the design of the program.

Basically, the implementation of the program went through a cycle of design, implementation, reflection, and modification according to researcher's observation and the students' interviews during the process, and then it repeated. The design of the program was flexible and adjustable for the purpose of helping the students' showing their possible motivational components and the interface with attractor states. Action research is chosen not only because the teacher serves as a researcher but also because the teacher has a chance to apply theoretically feasible methods to solve real problems in a natural educational context.

Another practical purpose for doing action research is to figure out solutions to the problems existing in the practical educational context. Altrichter, Posch, and Somekh (1993) indicated that action research provides the methods and strategies to investigate and improve practical teaching settings. Besides, Burns (1999) also indicated that action research is evaluative and reflective when it aims at exploring the main change and improvement in practice. The results of the research can be applied directly and immediately to the classroom to offer possible solutions to the existent problems. Action research helps to recognize and translate developing ideas into action.

\section{Participants}

Participants were 65 sophomores of Sport College chosen from the PE department and Dance department (35-PE; 30-Dance). These students all take the basic freshmen English course for one year. 25 participants have got another elective English course before. All participants were not passed the basic GEPT test. 48 participants joined the freshmen English course of the researcher one year ago.

\section{Procedures}

After watching a movie called "Romeo and Juliet", these participants answer the worksheet. There were three questions related to the movie plots; the last one is the open question for bringing out the triggers of motivation of choosing this course as the elective one. Open question for Phase 1: Why did you decide to choose this course in the first beginning of the semester? Please write down the reasons as clearly as possible.

After these students have their midterm ICP, the researcher interviewed 10 PE students (five for above 80 scores and five for under 80 scores) and 10 Dance students (five for above 80 scores and five for under 80 scores); and asked these students for three questions as Phase 2: (1) What do you think about the course so far? (2) Does the course meet your expectations in the first beginning? (3) Do you have any suggestions for the teacher about the course syllabus?

\section{Data Collection and Analysis}

All the data collection was obtained from the teacher reflections of the open question for 65 students in the first beginning of the semester (teacher is also the researcher), as well as student interviews of $10 \mathrm{PE}$ students and 10 Dance students. Student interviews were conducted individually. As to O’Malley and Chamot (1990), using the interview method to collect data on learning strategy can help to gain deep information and inspire the participants to respond more utterances.

In Phase 1, 65 participants watched a music movie called "Romeo and Juliet", and after the movie, they did the worksheet in class. There were three questions related to the plot of the movie, and the last question is 
an open question for inspiring them to show some motivational components which influences their will into choosing the elective English course. The open question is: Why did you decide to choose this course in the first beginning of the semester? Please write down the reasons as clearly as possible. The researcher read the answers of this question and categorized into three motivational components (see Findings and Discussions).

After eight weeks' lectures, the researcher asked students to do an in class presentation as their midterm. Then, the researcher chose 10 PE students (five for above 80 scores and five for under 80 scores) and 10 Dance students (five for above 80 scores and five for under 80 scores); and interviewed them for three questions as Phase 2: (1) What do you think about the course so far? (2) Does the course meet your expectations in the first beginning? (3) Do you have any suggestions for the teacher about the course syllabus? The interviews were conducted in Mandarin Chinese, the students' mother tongue. Before starting the interviews, the participants were informed that all the discussions of the interviews would be kept confidential and have no bearing on their midterm grades (See Appendix for the student interviews in raw data).

All data collected from the students' interviews, and teacher's reflections went through three main coding stages: open coding, axial coding, and selective coding (Strauss \& Corbin, 1998; Moghaddam, 2006). At the open coding stage, the data were split into units of meanings, incidents were put together as labels, and categorized concepts united into some clusters related to a certain theme. At the axial coding stage, the labels were reducing in the process of establishing the relationships among the possible codes. The process keeps relating sub-categories to a main category and adding the density of the categories by examining detailed variations. Finally, a core category was developed at the end of this stage. At the selective coding stage, core categories and their relationships to each other were investigated to picture a general idea of the results. When the researcher met difficulties in analyzing the data, she would trace back to the raw data and examine it from an alternative perspective through consideration of the study context. These core categories developed from the three coding stages were repeatedly examined to ensure the validity of the findings.

\section{Findings}

\section{Phase 1}

The researcher categorized the answers of these 65 students and coded into three variables of motivational components. Table 1 shows that percentage of categories:

Table 1

\begin{tabular}{lll}
\hline & PE & Dance \\
\hline Course-specific motives & $2 / 35(5.7 \%)$ & $4 / 30(13 \%)$ \\
Teacher-specific motives & $21 / 35(60 \%)$ & $20 / 30(66 \%)$ \\
Group-specific motives & $12 / 35(34 \%)$ & $6 / 30(20 \%)$ \\
\hline
\end{tabular}

Among these PE students, there were 21 students' answers related to the teacher-specific motives. Most of them mentioned that they took the teacher's freshmen English class and they all enjoyed the class. Hence, they chose the elective course just because of the teacher's name. Similarly, there also showed the same phenomenon in Dance students. They also presented the teacher-specific motives are the most important factor influencing their decisions for choosing the elective English course (20/30; 66\%).

\section{Phase 2}

Data were gathered by means of short, semi-structured interviews. Participants were informed that the 
study focused on classroom experience and were asked to answer three questions as follows: (1) What do you think about the course so far? (2) Does the course meet your expectations in the first beginning? (30 Do you have any suggestions for the teacher about the course syllabus?

In this phase of the study, different terms were used to describe the diversity of states students had experienced, although many of the terms overlapped. From the content analyses of these states three distinct categories emerged: interest, boredom, and neutral attention.

Interest. This category is a combination of the following descriptions: "interested", "engaged”, "curious", "active", and "enjoyment". These terms were often mentioned together, participants using one to explain or to elaborate another. Aspects of interest were mentioned by $98 \%$ of the participants. From these data, the concept can be summarized as active engagement and enjoyment emerged, bringing up to more active participation in the on-going learning activities. An example of how enjoyment, interest, and active attention converged is illustrated in the following quote:

In the beginning I didn't know the course's syllabus, and actually I didn't care about the English course anyway. But I'm getting more and more interested in the story discussion every week. In the end, I am looking forward to the class every Thursday. I didn’t take any class of this teacher, but I love her style so far. (Appendix PES5)

Interest, being the most frequently mentioned state, hence is an important attractor state in the learning experience, and its significance is not only for its overall frequency, but to its link to learners' active engagement and future motivational intention in the classroom.

Boredom. Another state mentioned by nearly $0 \%$ of the participants was, with some variation, boredom. Never heard descriptions were "zoning out”, being “distracted”, being "sleepy”, and "not paying attention” in their interview data. Boredom seems to be the polar opposite of interest. Whereas interest revolves around active participation and positive effect, boredom is passive and has no direct positive affective dimension.

Neutral attention. The third state some participants mentioned experiencing was, surprisingly, neither boredom nor interest. Yet rather a state somewhere in between the two: neutral attention. Less than $8 \%$ of participants described variants of this state in their interviews. Neutral attention is the type of situation where a learner is still paying attention in class, but is not necessarily actively engaging with the material, nor does he or she have any particularly intense affective reaction to the situation.

This is exemplified in the two quotes below:

I don't care about the scores and I don't like English either. But I love our English teacher. I think you should teach us other courses, like Martial Arts... (Appendix PES6)

I'm really poor at English, but the teacher never says anything bad about my accent or grammar issue. Teacher always encourages us to speak load and try to use English in any situation. That's very cool and I've never thought that I can get such high score on ICP. (Appendix DS5)

PES6's quote demonstrates the difference between neutral attention and boredom; a learner is still paying attention, as opposed to being bored where zoning out is a frequent occurrence. The quote of DS5 shows the fine line between anxiety and interest, so coded as neutral attention; while this learner might be paying attention, she will not process as much, or engage as actively, as during a state of interest with some level of anxiety where there is more energy. Although this state was not among the analyzed attractor states mentioned in the previous literature review session, it is not a brand new concept in the literature. A neutral state was also mentioned as one of the most frequently reported states in academic tasks in Ainley's (2007) study, and Baker 
et al. (2010) also found that in some learning environments a neutral state was most frequently observed (Waninge, 2015).

\section{Discussions}

As to the findings of these participants, students show higher intense of the willingness for the teacher-specific motives. Among these PE students, there were 21 students' answers related to the teacher-specific motives. Most of them mentioned that they took the teacher's freshmen English class and they all enjoyed the class. Hence, they chose the elective course just because of the teacher's name. Similarly, there also showed the same phenomenon in Dance students. They also presented the teacher-specific motives which are the most important factor influencing their decisions for choosing the elective English course (20/30;66\%).

The learning path of giving ICP certainly reveals the interaction within the attractor states, which triggers better self-regulatory learning strategies. After observing these correlations between the motives and attractor states in students' interview, this study proposed some insights of the interface with motivational components and attractor states. Future studies may also focus on investigating the significant relations between these motivational motives and the performance of attractor states.

\section{Conclusion}

This study presented that multi-faceted and unpredictable as the learning experience can in fact be studied systematically using a relatively simple dynamic systems-based research design. To aim at identifying attractor states that are expected to emerge in a self-organizing system, the variation in students' learning experience has been narrowed down to three main types; interest, boredom, and neutral attention. These states are frequently mentioned in the literature in educational psychology and second language acquisition, although they have mostly been treated from individual differences, rather than a dynamic systems perspective.

Although most participants mentioned that they may stay in one state within a single lesson, which is not indicative of variability on a short term time scale, there is inconsistent data that point to relatively stable "default states" featuring certain subjects, as reflected for example in participants' comments on how they were always interested in sport related classes, or were always really bored in English classes. The underlying attractor basin, causing the occurrence of a certain attractor state, is a combination of cognitive, motivational, affective, and contextual elements. Although there were not mentioned in this study for some limits, the different factors were mentioned separately; an important finding arising from the analysis of participants' narratives is the almost inseparable nature of cognition, motivation, effect, and context. This combination of factors often surfaces together in the language learners' accounts, supporting or triggering a student's interest by the way they interact and reinforce one another, hence making it difficult to separate their influence and calculate any straightforward causality. This finding is in accordance with the observations of other researchers who have emphasized the inseparability of emotion and cognition (Lewis, 2005; Swain, 2013), or of motivation, emotion, and cognition (Dai \& Sternberg, 2004).

Further research into the interaction of motivation, cognition, effect, and context might uncover attractor patterns in the learning experience in general and interest specifically. A possibly promising direction of research would be the situated longitudinal micro-mapping of different states within the learning environment (Nitta, 2013; Pawlak, 2012; Waninge, Dörnyei, \& de Bot, 2014). In order to analyze the variability of the learning experience, it needs some further discussion for investigating the relation to the context and its 
implications for the overall learner experience on a larger timescale.

\section{References}

Ainley, M. (2007). Being and feeling interested: Transient state, mood, and disposition. In P. A. Schutz and R. Pekrun (Eds.), Emotion in education (pp. 141-157). Oxford: Elsevier.

Altrichter, H., Posch, P., \& Somekh, B. (1993). Teachers investigate their work: An introduction to the methods of action research. London: Routledge.

Ames, C. (1992). Classrooms: Goals, structures and student motivation. Journal of Educational Psychology, 84, $267-271$.

Brown, H. D. (1994). Teaching by principles. Englewood Cliffs, NJ: Prentice Hall.

Burns, A. (1999). Collaborative action research for English language teacher. Cambridge, U.K.: Cambridge University Press.

Clément, R., Dörnyei, Z., \& Noels, K. A. (1994). Motivation, self-confidence, and group cohesion in the foreign language classroom. Language Learning, 44, 417-418.

Csikszentmihalyi, M. (1990). Flow: The psychology of optimal experience. New York: Harper \& Row.

Crookes, G., \& Schmidt, R. W. (1991). Motivation: Reopening the research agenda. Language Learning, 41(4), 469-512.

Dai, D. Y., \& Sternberg, R. J. (Eds.). (2004). Motivation, emotion and cognition: Integrative perspectives on intellectual functioning and development. Mahwah, NJ: Lawrence Erlbaum Associates.

Dewaele, J. M., Petrides, K. V., \& Furnham, A. (2008). Effects of trait emotional intelligence and sociobiographical variables on communicative anxiety and foreign language anxiety among adult multilinguals: A review and empirical investigation. Language Learning, 58(4), 911-960.

Dewey, J. (1913). Interest and effort in education. New York: Houghton Mifflin Company.

D’Mello, S., \& Graesser, A. (2012) Dynamics of affective states during complex learning. Learning and Instruction, 22(2), 145-157.

Dörnyei, Z. (1990). Conceptualizing motivation in foreign-language learning. Language Learning, 40(1), 45-78.

Dörnyei, Z. (1994a). Understanding L2 motivation: On with the challenge! The Modern Language Journal, 78, 515-523.

Dörnyei, Z. (1994b). Motivation and motivating in the foreign language classroom. The Modern Language Journal, 78, $273-284$.

Dörnyei, Z. (1998). Motivation in second and foreign language learning. Language Teaching, 31, 117-135.

Dörnyei, Z. (2003). Attitudes, orientations, and motivations in language learning: Advances in theory, research, and applications. Language Learning, 53(S1), 3-32.

Dörnyei, Z. (2005). The psychology of the language learner: Individual differences in second language acquisition. Mahwah, NJ: Lawrence Erlbaum Associates.

Dörnyei, Z. (2009). The psychology of second language acquisition. Oxford: Oxford University Press.

Gardner, R. C. (1985). Social psychology and second language learning: The role of attitudes and motivation. London: Edward Arnold.

Gardner, R. C., \& Lambert, W. E. (1972). Attitudes and motivation in second language learning. Newbury House: Rowley, MA.

Gardner, R. C., \& MacIntyre, P. D. (1993). On the measurement of affective variables in second language learning. Language Learning, 43, 157-194.

Hidi, S., Renninger, K. A., \& Krapp, A. (2004). Interest, a motivational variable that combines affective and cognitive functioning. In D. Y. Dai and R. J. Sternberg (Eds.), Motivation, emotion and cognition (pp. 89-115). Mahwah, NJ: Lawrence Erlbaum Associates.

Izard, C. E. (2011). Forms and functions of emotion: Matters of emotion-cognition interactions. Emotion Review, 3, 371-378.

Kemmis, S., \& McTaggart, R. (Eds.). (1988). The action research planner (3rd ed.). Victoria: Deakin University Press.

Lee Do, S., \& Schallert, D. L. (2004). Emotions and classroom talk: Toward a model of the role of affect in students' experiences of classroom discussions. Journal of Educational Psychology, 96, 619-634.

Lewis, M. D. (2005). Bridging emotion theory and neurobiology through dynamic systems modeling. Behavioural and Brain Sciences, 28, 169-245.

MacIntyre, P. D. (2002). Motivation, anxiety and emotion in second language acquisition. In P. Robinson (Ed.), Individual differences in second language acquisition (pp. 45-68). Amsterdam: John Benjamins.

MacIntyre, P. D., \& Gardner, R. C. (1994). The subtle effects of language anxiety on cognitive processing in the second language. Language Learning, 44(2), 283-305.

McGroarty, M. (2001). Situating second language motivation. In Z. Dörnyei and R. Schmidt (Eds.), Motivation and second language learning (pp. 69-90). Honolulu, HI: University of Hawaii Press. 
Moghaddam, A. (2006). Coding issues in grounded theory. Issues in Educational Research, 16(1), 52-66.

Nitta, R. (2013). Understanding motivational evolution in the EFL classroom: A longitudinal study from a dynamic systems perspective. In M. T. Apple, D. DaSilva, and T. Fellner (Eds.), Language learning motivation in Japan (pp. 268-290). Bristol: Multilingual Matters.

O’Malley, J. M., \& Chamot, A. U. (1990). Learning strategies in second language acquisition. Cambridge: Cambridge University Press.

Oxford, R. L., \& Shearin, J. (1994). Language learning motivation: Expanding the theoretical framework. Modern Language Journal, 78, 12-28.

Pawlak, M. (2012). The dynamic nature of motivation in language learning: A classroom perspective. Studies in Second Language Learning and Teaching, 2(2), 249-278.

Pekrun, R., Goetz, T., Daniels, L. M., Stupnisky, R. H., \& Perry, R. P. (2010). Boredom in achievement settings: Exploring control-value antecedents and performance outcomes of a neglected emotion. Journal of Educational Psychology, 102(3), 531-549.

Pekrun, R., Goetz, T., Titz, W., \& Perry, R. P. (2002). Academic emotions in students' self-regulated learning and achievement: A program of qualitative and quantitative research. Educational Psychologist, 37(2), 91-105.

Shernoff, D. J., Csikszentmihalyi, M., Schneider, B., \& Shernoff, E. S. (2003). Student engagement in high school classrooms from the perspective of flow theory. School Psychology Quarterly, 18(2), 158-176.

Silvia, P. (2005). What is interesting? Exploring the appraisal structure of interest. Emotion, 5, 89-102.

Skehan, P. (1989). Individual differences in second-language learning. London: Edward Arnold.

Strauss, A., \& Corbin, J. (1998). Basics of qualitative research: Techniques and procedures for developing grounded theory (2nd ed.). Thousand Oaks, CA: Sage.

Swain, M. (2013). The inseparability of cognition and emotion in second language learning. Language Teaching, 46(2), $195-207$.

Waninge, F., Dörnyei, Z., \& de Bot, K. (2014). Motivational dynamics in language learning: Change, stability and context. The Modern Language Journal, in press.

Waninge, F. (2015). Motivation, emotion and cognition: Attractor states in the classroom. In Z. Dörnyei, P. D. MacIntyre, and A. Henry (Eds.), Motivational dynamics in language learning (pp. 195-213). Bristol: Multilingual Matters. 


\section{Appendix}

\section{Phase 1}

Open question for 65 sophomores of Sport College was chosen from the PE department and Dance department (35-PE; 30-Dance).

Why did you decide to choose this course in the first beginning of the semester? Please write down the reasons as clearly as possible.

Table 1

\begin{tabular}{lll}
\hline & PE & Dance \\
\hline Course-specific motives & $2 / 35$ & $4 / 30$ \\
& $(5.7 \%)$ & $(13 \%)$ \\
Teacher-specific motives & $21 / 35$ & $20 / 30$ \\
& $(60 \%)$ & $(66 \%)$ \\
Group-specific motives & $12 / 35$ & $6 / 30$ \\
\hline
\end{tabular}

Phase 2: Interview questions

(1) What do you think about the course so far? (2) Does the course meet your expectations in the first beginning? (3) Do you have any suggestions for the teacher about the course syllabus?

PES1: I love this class. I didn't think too much at the beginning, but I really enjoy the class so far. Maybe teacher can give us more choices of stories. I didn’t like the story I picked out. But I have no other choice.

PES2: I really enjoy the class. I didn’t know we can watch some movies in class at the first beginning, so I'm so excited while watching the movies. If teacher can play more movies, that would be better.

PES3: I love Angel. Whatever Angel said would be ok to me. So I love to do the ICP and enjoy the preparation before getting on the stage. No need to change anything about you, teacher. We all love you. Please hold another elective course next semester.

PES4: I love this class. Teacher always gives us news and fancy stuff. Even the ICP looks like an impossible mission to me, I did it anyway. If teacher can show much more tips for presentation, that would be beneficial for me.

PES5: In the beginning I didn't know the course's syllabus, and actually I didn't care about the English course anyway. But I'm getting more and more interested in the story discussion every week. In the end, I am looking forward to the class every Thursday. I didn't take any class of this teacher, but I love her style so far.

PES6: I don't care about the scores and I don’t like English either. But I love our English teacher. I think you should teach us other courses, like Martial Arts...

PES7: I love this class, especially the teacher. We all love to take Angel's class. But we don't like ICP...to present an English story is quite hard for me. If we can take other ways to be the midterm exam, that would be better.

PES8: I really enjoy the class. Even my mate didn’t do his work on ICP, I can handle the presentation well by myself. I know the teacher wouldn't be too harsh for my poor PPT...you know, some teachers would criticize the PPT format on the spot. That makes me more nervous and gets a blank head totally.

PES9: Angel is so nice. I really enjoy your class. I spent a lot of time preparing the ICP, because I want to make an impressive effect on my presentation. I really bumped into some trouble while making the PPT, but I am so happy while I finish the PPT. I hope I can take other elective course of Angel's.

PES10: I am so surprised that my ICP can make such high score. I did a lot effort for preparing the PPT and I really enjoy the class so much. I love the English teacher. I would like to take other classes if Angel is the teacher. 
DS1: I love teacher's class so much. I don't think the time for ICP is enough for us, but I know there are too many students in the class... anyway, we all love Angel.

DS2: I felt frustrated while preparing the ICP, because I didn't understand the story quite well, especially there were few references I can find on the internet...it’s really a torture for me. But I love you, Angel. I think maybe I am not that kind of guy who can read thoroughly and give some inspiring feedback...

DS3: I really enjoy the class. I love to read stories and I love to watch movies. I've heard that the teacher would let us watch some movie related to the stories, so I am looking forward to being in the class every Thursday. It's the most interesting class I've ever taken.

DS4: At the beginning, I was quite worried about my poor English that might be some trouble while reading these stories. After these lectures, I found that I can easily understand the main ideas of the stories. I feel so satisfied with my ICP, by the way. I really enjoy this class and I hope there would be another course in the following semester.

DS5: I love Angel. I'm really poor at English, but the teacher never says anything bad about my accent or grammar issue. Teacher always encourages us to speak load and try to use English in any situation. That's very cool and I've never thought that I can get such high score on ICP. Thank you, teacher.

DS6: We all love the teacher. But we don't like the ICP...we thought that test would be easier for us to prepare. ICP took a lot of time and we didn't know how to prepare the discussion questions. If we can take another course next semester, would you please have no ICP?

DS7: I cannot believe that I can read these stories in such a short time. I think that teacher is so smart that you make each of us prepare different stories. I love this kind of evaluation. Maybe that's my area for teacher training program, I love ICP. But I know there are many classmates who didn't like ICP.

DS8: I really enjoy this class. Teacher gave us a lot funny stories and lets us discuss the possible solutions for some dilemma in some stories. Such like the first story, about a tiger and a lady. I love that kind of discussion. It makes me think deeply and thoroughly. Thank you, teacher.

DS9: We all love to take this course. Especially we all look forward to be in the class and listen to our teacher telling some interesting stories. Just like back to our childhood, while going to bed, mom always told some stories. Although ICP is not that easy to do, we all enjoy the preparation.

DS10: I love this course. At the beginning, I cannot choose this course online, then I felt so depressed. Then, one of my classmates sacrificed her chance, and she gave me the place that I can enroll in this course. I felt so lucky and thankful for her. I really love Angel's style. It's always free-speaking and thinking out loud as we like. 